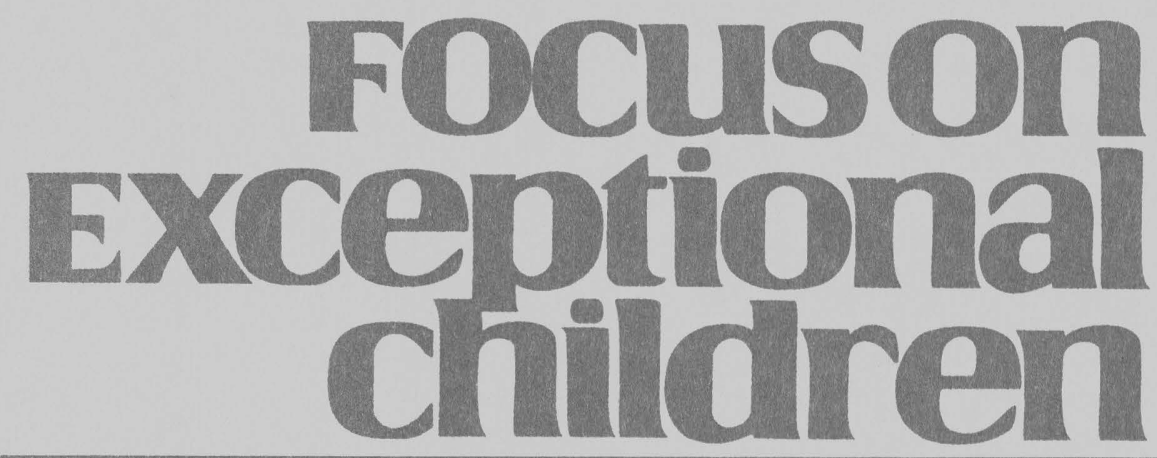

\title{
Preparing Youth with Disabilities for College: How Research Can Inform Transition Policy
}

\author{
Michael G. Wilson, Amanda V. Hoffman, and Margaret J. McLaughlin,
}

Special education policy as articulated through the Individuals with Disabilities Education Improvement Act (IDEA) focuses on improving the postschool outcomes of students with disabilities, including enrollment in college. The transition requirements of the 2004 IDEA amendments (P.L. 108-446) require school systems to determine postschool goals for youth with disabilities and to provide individualized transition services to enable them to reach those goals. College enrollment and access have recently become an important postsecondary outcome measure for students with disabilities (Horn, Berktold, \& Bobbitt, 1999). However, programming, transition services, and research have historically centered on increasing skills (e.g., self-determination, parental support, work-based learning) associated with independent living and postschool employability rather than with college enrollment (Bremer, Kachgal, \& Schoeller, 2003; Leucking \& Mooney, 2002; Roy \& Casper, 2006).

This focus has been justified by the dismal employment outcomes for many youth with disabilities, specifically those with moderate to severe intellectual and developmental disabilities. Notwithstanding, in recent years legislation has increasingly focused on promoting enrollment in two- and four-year colleges as a means of improving employment outcomes for all students with disabilities. The 1997 and 2004 amendments to IDEA included several new provisions that place a greater emphasis on ensuring youth with disabilities access to the general education curriculum and inclusion in state accountability programs. In addition, changes to transition provisions in the law require greater focus on developing a course of study for secondary students with disabilities that will lead to desired outcomes, such as college enrollment. Despite these efforts, relatively little research has been conducted to inform practice related to transition services leading to college enrollment.

\footnotetext{
Michael G. Wilson is a Postdoctoral Research Fellow at Teachers College, Columbia University. Amanda V. Hoffman is a Policy and Evaluation Research Associate II at WestEd. Margaret J. McLaughlin is a Professor and Associate Dean for Research and Graduate Education at University of Maryland at College Park and Associate Director for the Institute for the Study of Exceptional Children.
} 
This article will discuss what is known about the transition of youth with disabilities to college and will explore two major factors associated with college enrollment among youth in general. These are (1) youth aspirations to attend college (Hoffman, 2008) and (2) completion of a college preparatory curriculum (Wilson, 2008). We will present findings from two separate studies that utilized the Educational Longitudinal Study of 2002 (ELS:02) to examine how youth with and without disabilities differ with respect to their aspirations and college readiness. Findings from these studies provide implications for special and general educators as well as policy makers with respect to the high school experiences and opportunities of youth with disabilities who aspire to attend a two- or four-year college or university.

This article is divided into four sections. In the first section we review the evolution of federal transition policy with a particular focus on increasing college enrollments. In the second section we provide an overview of what we currently know about the research related to the transition of

\section{Focuson
Exceptional
childiren}

ISSN 0015-511X FOCUS ON EXCEPTIONAL CHILDREN (USPS 203-360) is published monthly except June, July, and August as a service to teachers, special educators, curriculum specialists, administrators, and those concerned with the special education of exceptional children. This publication is annotated and indexed by the ERIC Clearinghouse on Handicapped and Gifted Children for publication in the monthly Current Index to Journals in Education (CIJE) and the quarterly index, Exceptional Children Education Resources (ECER). The full text of Focus on Exceptional Children is also available in the electronic versions of the Education Index. It is also available in microfilm from Serials Acquisitions, National Archive Publishing Company, P.O. Box 998, Ann Arbor, MI 48106-0998. Subscription rates: individual, \$48 per year; institutions, \$66 per year. Copyright (c) 2009, Love Publishing Company. All rights reserved. Reproduction in whole or part without written permission is prohibited. Printed in the United States of America. Periodical postage is paid at Denver, Colorado. POSTMASTER: Send address changes to:

\section{Love Publishing Company \\ Executive and Editorial Office P.O. Box 22353 \\ Denver, Colorado 80222 \\ Telephone (303) 221-7333}

\section{EDITORIAL BOARD}

Lisa Dieker

University of Central Florida
Paula Maccini University of Maryland

Marleen Pugach

University of Wisconsin-Milwaukee

Carrie E. Watterson

Senior Editor
Stanley F. Love

Publisher youth with disabilities to college. We then discuss two studies that were conducted by the first and second authors that utilized the ELS:02, a multilevel longitudinal study of the high school and postsecondary experiences of the 2002 cohort of 17,591 U.S. 10th graders. The studies examine the curricular opportunities that influence math achievement and postsecondary educational plans (i.e., aspirations) among high school students with disabilities. We conclude with a discussion of the implications of these two research studies for transition policy as well as for the use of largescale databases in special education research.

\section{FEDERAL TRANSITION POLICIES}

As students with disabilities have gained access to public education, the post-high school outcomes of that education have become a primary area of interest for researchers and the Office of Special Education and Rehabilitation Services (OSERS). In the 1980s, several studies and reports (Halpern, 1985; Will, 1984) brought national attention to poor postschool outcomes among youth with disabilities. This resulted in a call to address the transition from high school to postschool employment and other outcomes for youth with disabilities.

The release of findings from the first National Longitudinal Transition Study (NLTS1; Wagner, Blackorby, Cameto, \& Newman, 1993) further increased attention to the postschool outcomes of youth with disabilities. The NLTS1 was a nationally representative study of a cohort of students with disabilities who were followed from 10th grade until five years after leaving school. The NLTS1 provided, for the first time, a national picture of the outcomes of youth with disabilities and confirmed that youth with disabilities were not successfully transitioning into postschool life (Wagner, Newman, Cameto, \& Levine, 2005). A second longitudinal study of transition, the NLTS2, began in 2000 . This nationally representative study of students with disabilities who were 13-16 years old during the 2000-2001 school year is collecting data through 2009 on the life experiences of students with disabilities. NLTS2 data include a number of variables pertaining to the high school experiences of these students, the services provided them, and postschool status.

In 1990, the Education of the Handicapped Act (EHA) was reauthorized and became the Individualized with Disabilities Education Act (IDEA). Among the changes made to the Act was the requirement that transition services be provided to all youth with disabilities. The reauthorized law provided a definition of transition services. This definition defined postschool outcomes to include "postsecondary education, vocational training, integrated employment (including supported employment), continuing and adult 
education, adult services, independent living, or community participation" (IDEA, 20 U.S.C. $1400 \S 602$ (30) (A-C)). In addition, other provisions were added to the law to "mandate ... [a transition plan] beginning not later than the first IEP to be in effect when the child is $16 "(\S 614$ (d)(1)(A)(i) $(\mathrm{VIII})$ ) and to include requirements that transition services (a) be based on multiple postsecondary outcomes and a coordinated set of activities, (b) include students in planning, (c) consider individual student interests and needs, and (d) include interagency collaboration among service providers as part of the planning process (Neubert, 2006). Despite changes made in the 1990 reauthorization of IDEA, Congress later found that additional changes to the law were needed to further improve outcomes for students with disabilities ( $\$ 601$ (c)(5)). Among these changes was a focus on the coordination of transition services and access to the general education curriculum.

The 1997 IDEA reauthorization modified transition requirements to include a statement of transition services focus on the youth's course of study (§ 614 (d)(1)(A)(viii) (I)). The law required the statement of transition services to be updated annually. Additionally, it required schools to increase the opportunities of students general education curriculum (§ $614(\mathrm{~d})(1)(\mathrm{A})(\mathrm{i})(\mathrm{I}))$. As a result, teams that develop transition goals and services as part of the individualized educational plan (IEP) were required to determine students' present level of performance in the general education curriculum and to develop supports and services that would allow students with disabilities to participate and make progress in the general education curriculum (Neubert, 2006). Access to the general education curriculum was further reinforced by the requirement that students with disabilities participate in district- or state-wide testing programs under No Child Left Behind (NCLB; McLaughlin, Embler, \& Nagle 2004).

The 2004 reauthorization of IDEA furthered the focus on improving academic outcomes for students with disabilities by setting goals and expectations aligned with those established for all children (e.g., NCLB) to "the maximum extent possible" ( $\$ 601$ (c)(5)). Notably, the 2004 IDEA definition of transition services states that services should be a coordinated "results-oriented process that is focused on improving the academic and functional achievement of the child with a disability to facilitate movement from school to postschool" ( $\$ 602(34)(A))$. Postschool goals must be based on the "child's strengths" (§602 (34)(B)) along with preferences, interests, needs, and age-appropriate transition assessment. Thus, transition services must provide an opportunity for youth with disabilities to identify postschool goal(s), develop a course of study to assist in meeting those goals, and identify supports needed to aid in the transition after school (34 CFR 300.320(b) and (c); 20
U.S.C. $1414(\mathrm{~d})(1)(\mathrm{A})(\mathrm{i})(\mathrm{VIII}))$. Through this language, the law extends the 1997 definitional requirement beyond simple access to the general education curriculum and positions access to the curriculum as a means to achieving postschool goals. Thus, for students with college aspirations, transition services must primarily focus on developing a course of study that prepares them for college matriculation. In the next section, we discuss the current research related to youth with disabilities and enrollment in college.

\section{COLLEGE ENROLLMENT AMONG YOUTH WITH DISABILITIES: THE RESEARCH BASE}

As noted earlier, most of the transition research has focused on the skills associated with increasing independent living, employment, and postsecondary (not necessarily college) education among students with disabilities. Transition research has relatively little to offer with regard to the $47 \%$ of students with disabilities whose goal, according to data from the NLTS2, is to attend a two- or four-year college after high school (Cameto, Levine, \& Wagner, 2004). The research that does exist is primarily descriptive and has utilized data from NLTS1, NLTS2 and the National Educational Longitudinal Study: 88 (NELS:88). Both NLTS1 and NLTS2 followed a cohort of youth with disabilities as they transitioned from high school to postschool life. The most current information regarding the transition practices in secondary schools is derived from the NLTS2 survey. NLTS2 data address important transition issues such as students' involvement in their own IEP development, placement, aspirations, and transition decisions (Cameto, Levine, \& Wagner, 2004). Thus, findings from the NLTS2 can provide some information on postschool aspirations and course of study as they relate to college enrollment for students with disabilities.

Findings from the NLTS2 indicate that $47 \%$ of the youth with disabilities in the sample had a postschool goal to attend a two- or four-year college or university. However, only $10.4 \%$ of parents of a child with a disability believed that their child "definitely will" graduate from a two-year college and 7.4\% believed that their child "definitely will" graduate from a four-year college or university (Newman, 2006). In addition to college aspirations, course rigor is an important indicator of both college enrollment and success (Choy, Horn, Nuñez, \& Chen, 2000; Rose \& Betts, 2001). The NLTS2 data suggests that students with disabilities are not well prepared for college enrollment. In the NLTS2 sample, $69 \%$ of youth with disabilities took general education classes (Wagner, Newman, Cameto, Levine, \& Marder, 2003); however, the type of course-taking varied across subject areas and grades. In general, students with disabilities took fewer academic courses 
during the last two years of high school when advanced courses are typically taken. Students with disabilities took more pre-vocational and vocational courses during the last two years of high school (Wagner et al., 2003). Other research on the college readiness of students with disabilities offers similar conclusions on the academic preparation of students with disabilities.

Horn et al. (1999) used the NELS:88 to determine the percent of students with disabilities prepared to enter a four-year college or university. The NELS:88 followed a nationally representative sample of eighth grade students for 12 years. The study used a combination of surveys and direct assessments to collect information on student perceptions, aspirations, experiences at home and school, as well as their academic achievement. Horn et al. (1999) found that in the NELS: 88 sample, $56 \%$ of students with disabilities were "not qualified" and only $15 \%$ were "very" to "highly qualified" for college. In addition to lagging scores on admissions criteria (GPA and SAT), Horn et al. concluded that students with disabilities were less likely to be prepared to enter a four-year college because they were more likely to have taken remedial courses and less likely to have taken advanced placement courses in mathematics and English. However, the age of the NELS: 88 sample makes inference to the current population of students with disabilities difficult.

Hitchings, Retish, and Horvath (2005) examined records of 110 students who graduated from two high schools in Illinois to determine the types of postschool goals and the rigor of course planning. The researchers found that only $5 \%$ of youth with disabilities had taken the college preparatory coursework to attend a four-year college or university. As noted earlier, national data seem to echo these findings, as they show students with disabilities moving toward less rigorous coursework as they progress through high school (Wagner et al., 2003). However, findings from the sample used in the Hitchings study cannot be generalized across schools and students with disabilities.

\section{COLLEGE READINESS AND ASPIRATIONS AMONG STUDENTS WITH DISABILITIES}

In this section, we review two studies that analyzed large-scale nationally representative databases to examine youth with disabilities in high schools. The two studies had different purposes; however, both highlight the impact of high expectations, aspirations, and access to academic curricula on academic preparation and enrollment in a two- or four-year college or university. Before discussing these two studies in detail, we first draw attention to several largescale federal databases that have the potential to be a source for answering important transition related policy questions in special education.

\section{Nationally Representative Studies}

A number of nationally representative studies have been supported by the U.S. Department of Education (USDOE). These studies have been designed to examine a variety of factors related to the education of children and youth with and without disabilities. The data from these studies provide researchers and policy makers with valuable information about the characteristics of children, youth, their families, and their experiences in U.S. schools. Because of their large samples, multi-stage probability samples, and breadth of coverage, these data provide researchers an opportunity to examine important issues of policy and practice that effect student learning. Using appropriate methods, these data allow researchers to examine how processes that occur at one level, such as placements/settings, affect processes that occur at a lower level, such as student achievement and learning (Raudenbush \& Bryk, 2002).

Within the USDOE, the National Center for Education Statistics (NCES) has conducted several longitudinal studies that have followed youth from high school through postschool since the 1970s under the National Education Longitudinal Studies Program (Schneider, Conroy, Kilpatrick, Schmidt, \& Shavelson, 2007). These studies have evaluated the impact of education experiences, community factors, and other resources on postschool outcomes, including postsecondary education, employment, marital status, and financial independence. These studies are: the National Longitudinal Study of 1972 (NLS:72), High School and Beyond of 1988 (HS\&B:1988), the National Educational Longitudinal Study of 1988 (NELS:88), and the current Educational Longitudinal Study of 2002 (ELS:02). In the early longitudinal studies, students with disabilities were not identified or were defined through unsystematic procedures (McDonnell, McLaughlin, \& Morison, 1997). Following criticism over methods used to exclude $5 \%$ of students with disabilities identified in the NELS:88 sample (McGrew, Thurlow \& Spiegel, 1993), NCES improved methods for identifying and collecting data on youth with disabilities (Ingels, Pratt, Rogers, Siegel, \& Stutts, 2004). As a result, special education researchers now have the opportunity to examine broad schooling issues such as school effects and educational opportunities as they relate to youth with disabilities and/or in comparison to youth without disabilities. The two studies discussed in this article utilized the ELS:02 data set.

\section{Educational Longitudinal Study of 2002}

The ELS:02 is a longitudinal study that follows a nationally representative sample of youth who were in 10th grade in 2002 for 10 years. The purpose of the study is to collect information relevant to policy, such as school processes, student experiences, and outcomes (Ingels, Pratt, Rogers, 
Siegel, \& Stutts, 2004). The ELS:02 uses a two-stage sampling design with schools as the primary sampling unit (PSU). Since schools were the PSU and students were selected within sampled schools, the ELS:02 database is appropriate for modeling the effects of schools on students. Additionally, the method of sampling was designed to arrive at a nationally representative sample of youth in 10th grade in 2002 and youth in 12th grade in 2004. The final sample for the ELS:02 base year (2002) to first follow up (2004) was 16,373 students in 752 schools.

Within selected schools, approximately 26 of the 10th grade students in the 2001-2002 school year were selected. Individual students in the ELS:02 will be followed for 10 years, with school-based assessments occurring in 2002 and 2004 (10th and 12th grades). Data for the ELS:02 were collected from students, parents, teachers, administrators, and school librarians. Student instruments included direct assessments of mathematics and reading as well as a survey of school experiences, self-perceptions, future plans, and family. Survey information was collected from the student's parent(s), reading and math teacher(s), as well as school administrators and a school librarian. Additionally, as part of the 2004 (senior year) first follow-up, transcript data were collected on all students. The transcript data consisted of school data on student course completion history, grades, attendance, and SAT or ACT scores. Below, we provide a brief description of the ELS:02 sample, assessments, questionnaires, and transcript information.

\section{Excluded students and schools}

The following types of students were excluded from the ELS:02 sample: foreign students, students whose command of English was insufficient for understanding materials, and students with disabilities whose level of functioning made assessment impractical or not useful. With regard to inclusion of students with disabilities, the ELS:02 instructed school officials to err on the side of inclusion when making decisions on students' ability to participate. Thus, we would expect the ELS:02 sample to overrepresent students with high-incidence or mild disabilities and underrepresent those with cognitive or intellectual disabilities. Additionally, several types of schools were excluded from the sampling frame, including schools with no 10th grade, closed schools, schools not enrolling students, Department of Defense schools, ungraded schools, Bureau of Indian Affairs schools, detention centers, correctional facilities, and special education schools.

\section{Direct assessments}

The ELS:02 math assessment items tested students on basic skills through advanced high school mathematics including arithmetic, algebra, geometry, data/probabilities, and advanced topics. The test content was based largely on existing content items from the National Assessment of Education Progress (NAEP), Program for International Student Assessment (PISA), and NELS:88. Like its predecessors, the ELS:02 math assessment items were largely multiple-choice $(90 \%)$. Assessment scores were estimated using Item Response Theory (IRT) as opposed to actual student responses on each individual test item. Assessments scored using IRT provide theta scores and do not produce traditional psychometric properties (e.g., reliability and validity), therefore these data were not available. For further description of IRT see Beaton and Johnson (1992).

\section{Student questionnaire}

Tenth grade students who participated in the ELS:02 completed a 45-minute self-report survey. The self-report had seven sections and asked students about their school experiences, future plans, foreign language use, work, family, and personal beliefs about themselves. The section on school experiences was the most extensive. In this section students were asked about their schools' climate, their level of engagement in school, their perceived curricular track, the learning environment in their school, time spent on homework, and use of school facilities.

The first follow-up included seven types of student questionnaires: student questionnaire (administered to the original sample), dropout questionnaire, early graduation questionnaire, transfer student questionnaire, home school questionnaire, and new participant student questionnaire (NPSQ). The first follow-up student questionnaire included eight sections: future contact information; school experiences and activities; how you spend your time; plans and expectations for the future; education after high school; work after high school; work for pay; and community, family, and friends. The transfer questionnaire was an abridged version of the student questionnaire with additional questions regarding the student's reason for transferring. The first follow-up had a $90 \%$ response rate.

\section{Parent questionnaire}

The parents of 10th grade students who were included in the sample were asked to voluntarily participate in a parent questionnaire during the base year (2002) of the survey. The questionnaire includes items that address family background (e.g., education level, race/ethnicity, religious affiliations, occupation, languages used in the home), parent perceptions of the school life of their child, and parent opinions of their child's school.

\section{Teacher questionnaire}

Both the English and Math teachers of students included in the sample completed teacher questionnaires. Teacher 
response data were intended to provide information on factors that may influence student performance in school.

\section{School administrator questionnaire}

School administrators were asked to provide information on school characteristics, the students and teachers within the school, policies, programs, technology, and the school climate. Data collected in the school administrator questionnaire provide information that indicates organizational or contextual realities in schools. Data were collected in both the base year and first follow-up.

\section{Transcript data}

The ELS:02 transcript study is an extension of NCES transcript studies that began with High School and Beyond in 1982 (Bozick et al., 2006). Transcript data provide reliable measures of educational experiences of students, including courses taken in high school, course grades, gradepoint average (GPA), SAT/ACT scores, competency and advanced placement test taking, and school course offerings. Full transcript records were retained for $86 \%$ of the sample students.

\section{Overview of Study Samples \\ Youth with IEPs in ELS:02}

The ELS:02 contains multiple variables to identify youth with a disability in the study sample. These included parent questionnaires, student questionnaires, teacher questionnaires, high school transcripts, and the school roster collected at the time of sample selection. For the studies discussed in this article, the ELS:02 IEP status variable was used as the initial identifier of students with disabilities, since the variable source was school administrator's roster information and was therefore viewed as more reliable than subjective questionnaire responses from parents or teachers. However, the IEP status variable contained a large amount of missing data $(n=7,735)$. Therefore, we used special education resource course credit information from the ELS transcript file to logically impute data on students' disability status. Students who received credits in a course labeled special education under the ELS coding system, such as the special education resource room course, are likely students with disabilities, as students without disabilities could not legally receive credits in such a course. This method significantly increased the subsample of students who were identified with disabilities in the ELS:02 from 1,031 to 2,513. While we expect that this method allowed us to identify all students with disabilities in the sample who enrolled in special education courses, we recognize that the method is limited, as it will not identify those students with IEPs that did not take special education classes during high school.

\section{Weights}

ELS:02 includes sampling weights to adjust for unequal probabilities of selection at both the student and school level. ELS:02 has a single school level weight for the baseyear sample of schools, which was representative of high schools in 2002. In these studies, the weight chosen represented youth included in both the 10th and 12th grade data collection cohort and renormalized with the reduced sample size. Thus, only youth who remained in their base year high school could be included in the analysis.

\section{Study 1 sample}

The second author selected youth in this study who participated in the 10th grade and first follow-up, had high school transcripts, had not transferred high school between 10th grade and first follow up, and had responded to the postsecondary education plan question. The study included 4,818 youth from 489 schools in which 912 were identified as having an IEP.

Youth in the analytic sample were significantly more likely to be male and members of a minority group than their peers without disabilities. Youth with disabilities were also of lower SES (-0.22 vs. 0.11) than youth without disabilities. Further, youth with disabilities were less likely to plan to attend a two- or four-year college after high school. Among students who plan to attend, students with disabilities had lower average GPAs (2.47 vs. 2.93 ), and did not advance as far in their math course-taking (4.67 vs. 5.88 ) as students without disabilities.

\section{Study 2 sample}

The first author selected youth who were 10th graders in the 2002 base year sample and 12 th graders in the 2004 first follow-up at the student level. Further, the subsample was restricted to students with known disability status, personal demographic data, 12th grade assessment score data, four years of transcript data, and 9th grade GPA data. Finally, the sample was restricted to youth for whom school level administrator data and school size data was available. The sample included 6,398 students in 608 schools, 1,600 of which were students with an IEP.

Youth with disabilities in the sample were significantly $(\mathrm{p}<.001)$ more likely to be male ( $56 \%$ vs. $47 \%)$, and nonAsian minority ( $39 \%$ vs. $26 \%$ ) than their peers without disabilities. The analysis of student characteristics indicated that students with disabilities were of lower SES (ES $=-.47)$, had lower academic GPAs at the start of high school (ES = -.42), did not advance as far in the math curriculum (ES = -.66), and had lower 12th grade math achievement in comparison to their peers without disabilities $(\mathrm{ES}=-.73)$. 


\section{Study 1: Educational Plans and Academic Experiences}

The second author's study used the ELS:02 data to examine differences in demographic and academic characteristics between youth with and without disabilities who plan to attend a two- or four-year college. Planning to attend college at spring of 12th grade was used as a proxy for attendance in higher education as college enrollment data were not yet available. Tenth grade postschool educational aspiration was designed to be the postschool goal required for a youth with disabilities transition service. There were two main purposes of the study with two research questions addressing the first purpose and a third research question addressing the second. The first purpose of this study was to compare plans to attend a two- or four-year college among youth with disabilities and between youth with and without disabilities on selected variables. The second purpose was to identify the relative contribution of selected family, student, academic, and school contextual factors in predicting plans to attend a two- or four-year college or university after graduation among students with and without disabilities.

\section{Measures}

The variables included were taken from the parent survey in 10th grade or the student or administrator survey in either 10 th or 12 th grade. The dependent variable in two of the research questions was a youth's plans to attend postsecondary education immediately after high school in the spring of the 12th grade. The variable was collapsed into a binary variable, with youth who planned to attend two- or four-year college or university being coded one and all other plans (i.e., no plans, unsure, vocational/technical school) coded zero. The other dependent variable examined in this study was the IEP variable noted above. Finally, 12 independent variables were used in the study, including race/ethnicity, gender, socioeconomic status (SES), parental education, parental educational expectations for youth in 10th grade, youth educational aspirations in 10th grade, math pipeline, GPA, high school track, percent free and reduced lunch (FARMS) in a school, and urbanicity of school. In the third research question, the variables were entered across four models: IEP, academics (i.e., math pipeline, GPA, college prep), demographics (i.e., gender, race/ethnicity, SES, parental education, parental educational expectations), and school characteristics (i.e., percent FARMS, urbanicity).

\section{Data Analysis}

Research questions one and two used chi-squares and t-tests to compare differences between groups, in addition to reporting the frequency and means (when appropriate). The third research question used a form of Hierarchal Linear Modeling (HLM) for binary outcomes, called Hierarchal General Linear Modeling (HGLM).

\section{Results}

The results indicate that the group of youth with disabilities who planned to attend a two- or four-year college was unlike their peers with or without disabilities who did not plan to attend. To establish a baseline, the author evaluated the percent of youth with disabilities who planned to attend a two- or four-year college or university in spring of 12 th grade. Sixty-nine percent of youth with disabilities planned to attend versus $85 \%$ of youth without disabilities. Seventysix percent of youth with disabilities who planned to attend a two- or four-year college or university in 10th grade maintained their plans in the spring of 12th grade.

In terms of academics, youth with disabilities who planned to attend a two- or four-year college or university were more likely to take more advanced math coursework than their peers with disabilities who did not plan to attend. Further, students with disabilities who planned to attend were also more likely to report being on a college preparatory track and having a higher GPA than youth with disabilities who did not plan to attend. However, youth with disabilities did not reach the same level of math coursework, were less likely to report being on a college preparatory track, and had lower GPAs than their peers without disabilities who also planned to attend a two- or four-year college or university.

In the HGLM analysis, having an IEP was significantly and negatively associated with a youth's plans to attend a two- or four-year college or university in spring of 12 th grade. When the three academic variables (i.e., GPA, math pipeline, and high school track) were introduced to the second model, the impact of having an IEP dropped significantly, though it remained significant. Additionally, there was an unexpected finding in the relationship between GPA and IEP. The impact of GPA, in either direction, on the plans of youth with disabilities for college attendance was far less than for their peers without disabilities.

\section{Study 2: Math Curriculum Structure of Students with IEPs}

The purpose of the first author's study was to understand how school curriculum structure influences the math coursetaking and achievement of students with and without disabilities. The author also sought to examine the effects of school climate and composition within the models of curriculum structure.

\section{Measures}

The author used the ELS:02 item flag for students with an IEP and a measure of credit received in a special education resource class from the student transcript file to create a measure of youths' disability status. Composite measures 
of student race and SES as well as a measure of gender were taken from the ELS:02 survey data. GPA in 9th grade academic courses (e.g., mathematics, science, English, social studies, language (non-English), and fine arts) was also included as a student level predictor variable. Finally, the ELS:02 math pipeline variable was included. The ELS:02 math pipeline variable captures movement through the hierarchy of secondary level math coursework.

In order to measure the effects of school level variables on student outcomes, the first author used an ELS:02 measure of school size and created a five-component measure of school climate using principal components analysis. The five components that measured school climate were labeled Attendance Problems; Drug and Alcohol Problems; Gang or Racial Tensions; Disorderly Climate; and Theft, Vandalism, and Physical Conflicts. Additionally, student level measures of 9th grade academic GPA, highest math course taken, and SES were aggregated and used as school level measures of average achievement, average course-taking, and average SES, respectively. Finally, the first author aggregated the within-school standard deviation of the highest math course taken variable to measure the extent to which student course-taking was varied or constrained within schools.

This study included two dependent variables. For the model of school effects on math achievement, the dependent variable was the average 12th grade math IRT score from the ELS:02 math assessment. For the model of school effects on course taking, the dependent variable was the average highest math course taken from the math pipeline variable. A discussion of the math pipeline variable properties as an outcome variable is available in Burkam, Lee, and Smerdon (1997).

\section{Data analysis}

The first author used descriptive and bivariate statistics to compare the demographic, academic, and course-taking characteristics of students with disabilities to their peers without disabilities. Effect sizes were calculated and are discussed according to the definition $(.20=$ small, $.50=$ moderate, $.80=$ large) established in Cohen (1992). The author modeled the effects of school composition, climate, and curriculum structure using hierarchical linear modeling (HLM). The models in this study rely on statistical adjustment (i.e., ANCOVA) to address selection bias. Since all variables in the model were standardized, the gamma coefficients produced in the HLM models represent effect sizes in SD units.

\section{Results}

Analysis of the multilevel models indicated that being a student with a disability in a school with a constrained curriculum was associated with an average increase in math achievement (.29). In other words, a curriculum structure where most students take the same level of math coursework and that level of coursework includes advanced level math is associated with higher average math achievement for students with and without disabilities. The analysis also indicated that schools with highly variable course taking were associated with significantly lower average course taking among students with disabilities (-.81). School composition and climate affected the level of course taking and math achievement of students with disabilities; however, these effect sizes were smaller than those related to curriculum structure.

\section{DISCUSSION}

The findings of study 1 indicate that the majority of youth with disabilities maintain their postsecondary educational plans between the 10th and 12th grades. Additionally, academic success plays an important role in improving the likelihood youth will plan to attend college. Therefore, planning a course of study early is likely crucial in providing the student the greatest opportunity, in terms of their preparation for college. Though students with disabilities who plan to attend college appear better off academically than their peers with disabilities who do not plan to attend, their academic opportunities in mathematics remain limited in comparison to peers without disabilities. Students with disabilities do not obtain the same level of academic opportunity in terms of math coursework, which has implications for their postschool opportunities.

In study 2 , the findings suggest that the structure of curriculum matters in the math course-taking choices and achievement of students with disabilities. Thus, schools shape students' course of study in mathematics by limiting or broadening the available math classes that make up the curriculum. For some students with disabilities, this suggests that raising course-taking expectations in mathematics can have a positive effect on their course-taking and achievement. The course of study that students with disabilities complete in mathematics can impact their ability to access colleges and universities.

Taken in concert, these studies suggest that the college aspirations of students with disabilities are influenced by their own academic preparation and success and that preparation, in terms of math course-taking, can be influenced by the expectations that schools place on students. In other words, the academic expectations of schools for students, as expressed in the level of coursework students take, explains some of the variability in math course-taking and achievement among students with disabilities. In turn, students' own math course-taking and achievement explains some of the variability in their postschool college and university aspirations. Given the impact of curriculum structure on 
course-taking, and course-taking on achievement and plans for attending a two- or four-year college, the findings of these studies have notable implications for transition planning for students with disabilities with college aspirations.

\section{Implication for Transition Policy}

Many students with disabilities have and sustain plans to attend college between the 10th and 12th grades. However, their course of study does not always align with their college aspirations. In light of research that suggests that early Algebra course-taking improves math achievement of low achieving students (Gamoran \& Hannigan, 2000) and may lead to more advanced mathematics course-taking in high school (Smith, 1996), transition planning may need to begin sooner than federal law currently requires. Since course of study can be influenced by the expectations codified in school policies (i.e., constrained curriculum), students with disabilities who have college aspirations should be required to take Algebra by the ninth grade. Transition planning would need to begin prior to ninth grade to allow educators, parents, and students to develop a plan that will consider any need for remediation of prerequisite skills and supplemental programming that will allow for the development of a college preparatory course of study through high school.

\section{Limitations and Research Implications}

This article is intended to highlight the utility of largescale databases in the study of special education transition policy issues. As illustrated in the studies presented in this article, these datasets can be useful for comparing average outcomes of students with disabilities among schools and to their peers without disabilities. The large nationally representative samples provide the opportunity for powerful analyses from which, where appropriate, we may infer population statistics. Further, studies like the ELS:02 which use schools as the PSU provide an opportunity for special education researchers to ask questions about how the contexts and practices of schools affect students with disabilities. We believe this is an important step in broadening research in special education beyond examining how specific practices affect individual students to exploring aggregate effects of policy on special education populations. The two studies discussed here add to the literature on the plans of students with disabilities to attend two- or four-year colleges or universities in relation to the high school academic opportunities that predict attendance.

It should be noted that not all research questions can be addressed through the use of large-scale databases. The selection of a dataset necessarily limits the types of questions that the researcher may ask. Thus, the use of large-scale databases is not a research panacea but one of a number of empirical tools that should be used in special education policy research.

In addition to limitations in the types of research questions that can be addressed with the current large-scale databases of the NCES, many of these datasets also have limitations related to their general education focus. For example, the extent of missing data on the IEP status variable of the ELS:02 clearly indicates a continued lack of focus on analysis based on disability. Additionally, the ELS:02 does not attempt to examine issues of curricular enactment (e.g., IEP implementation, academic services) that could enlighten researchers as to which school or schooling factors help to explain the improved outcomes for students with disabilities in schools with a constrained curriculum. Adequate measures of disability status and the unique experiences and outcomes of students with disabilities within schools should be included in future nationally representative longitudinal studies of schools and student outcomes.

Finally, analyses done on large-scale datasets suffer from the same limitations as all secondary analyses of extant data (Thompson, Diamond, McWilliam, Snyder, \& Snyder, 2005). Both of the studies discussed in this article relied on statistical adjustments to address issues of selection bias. As noted elsewhere in the literature, statistical adjustment has limited utility for dealing with issues of selection bias. However, in the absence of random assignment to treatment, researchers have developed methods for making treatment assignment 'highly ignorable' (Schneider et al., 2007; Rubin, 1974; Rosenbaum, 1986). It is important that in addition to expanding the use of large-scale data, special education researchers be trained to use largescale datasets and, consequently, analytical methods for approximating causal inference and modeling effects at multiple levels.

Support for this research was provided in part by Cooperative Agreement No. H3252060002 of the U.S. Department of Education, Office of Special Education Programs, awarded to the University of Maryland. The opinions expressed do not necessarily reflect the positions or policies of the Department of Education and no official endorsement should be inferred.

\section{REFERENCES}

Beaton, A. E., \& Johnson, E. G. (1992). Overview of the scaling methodology used in the National Assessment. Journal of Educational Measurement, 29(2), 163-175.

Bozick, R., Lytle, T., Siegel, P. H., Ingels, S. J., Rogers, J. E., Lauff, E., \& Planty, M. (2006). Education Longitudinal Study of 2002: First Follow-up Transcript Component Data File Documentation. U.S. Department of Education. Washington, DC: National Center for Education Statistics. [NCES 2006-338]. 
Bremer, C. D., Kachgal, M., \& Schoeller, K. (2003). Self determination: Supporting successful transition. National Center on Secondary Education and Transition, Research to Practice Brief, 2(1). Minneapolis, MN: University of Minnesota.

Burkam, D. T., Lee, V. E., \& Smerdon, B. A. (1997). Mathematics, Foreign Language, and Science coursetaking and the NELS:88 Transcript Study. Ann Arbor: University of Michigan.

Cameto, R., Levine, P., \& Wagner, M. (2004). Transition planning for students with disabilities. A Special Topic Report of Findings from the National Longitudinal Transition Study-2 (NLTS-2). Retrieved October 1, 2009, from http://www.nlts2.org/reports/2004_11/nlts2 _report_2004_11_complete.pdf

Choy, S. P., Horn, L. J., Nuñez, A., \& Chen, X. (2000). Transition to college: What helps at-risk students and students whose parents did not attend college. In A. F. Cabrera \& S. M. La Nasa (Eds.), Understanding the college choice of disadvantaged students (pp. 45-63). San Francisco, CA: Jossey-Bass.

Cohen, J. (1992). A power primer. Psychological Bulleting, 112(1), 155-159.

Gamoran, A., \& Hannigan, E. C. (2000). Algebra for everyone? Benefits of college-preparatory mathematics for students with diverse abilities in early secondary school. Education Evaluation and Policy Analysis, 22(3), 241-254.

Halpern, A. S. (1985). Transition: A look at the foundations. Exceptional Children, 51(6), 479-486.

Hitchings, W. E., Retish, P., \& Horvath, M. (2005). Academic preparation of adolescents with disabilities for postsecondary education. Career Development for Exceptional Individuals, 28(1), 26-35.

Hoffman, A. V. (2008). Examining the plans of youth with disabilities to attend a 2-or 4-year college or university. Unpublished doctoral dissertation, University of Maryland, College Park.

Horn, L., Berktold, J., \& Bobbitt, L. (1999). Students with disabilities in postsecondary education: A profile of preparation, participation, and outcomes (NCES 1999-187). Washington, DC: U.S. Department of Education, National Center for Educational Statistics.

Individuals with Disabilities Education Improvement Act, 20 U.S.C. § 1400 et seq. (1997).

Individuals with Disabilities Education Improvement Act, 20 U.S.C. § 1400 et seq. (2004).

Ingels, S. J., Pratt, D. J., Rogers, J. E., Siegel, P. H., \& Stutts, E. S. (2004). Educational longitudinal study of 2002: Base year data file user's manual (NCES 2004-405). Washington, DC: U.S. Department of Education, National Center for Educational Statistics.

Luecking, R., \& Mooney, M. (2002). Tapping employment opportunities for youth with disabilities by engaging effectively with employers. National Center on Secondary Education and Transition, Research to Practice Brief, 1(3). Minneapolis, MN: University of Minnesota.

McDonnell, L., McLaughlin, M. J., \& Morison, P. (1997). Educating one \& all: Students with disabilities and standards-based reform. Washington, DC: National Academy Press.

McGrew, K. S., Thurlow, M. L., \& Spiegel, A. N. (1993). An investigation of the exclusion of students with disabilities in national data collection programs. Educational Evaluation and Policy Analysis, 15(3), 339-352.

McLaughlin, M. J., Embler, S., \& Nagle, K. (2004). Students with disabilities and accountability: The promise and the realities-should there be alternative? Center on Education Policy. Retrieved October 1, 2009, from http://www.cepdc.org/document/docWindow. cfm?fuseaction $=$ document. viewDocument $\&$ documentid $=217 \&$ do cumentFormatId $=3515$
National Center for Special Education Research (Institute of Education Sciences). (2007). Projects and programs. Retrieved September 4, 2009, from http://ies.ed.gov/ncser/projects/

Neubert, D. A. (2006). Legislation and guidelines for secondary special education and transition services. In P. L. Sitlington \& G. M. Clark (Eds.), Transition education and services for youth with disabilities. Boston: Pearson.

Newman. L., (2006). Facts from NLTS2: General education participation and academic performance of students with learning disabilities. Menlo Park, CA. Retrieved October 1, 2009, from http:// www.nlts2.org/fact_sheets/2006_07.html

Raudenbush, S.W., \& Bryk, A. S. (2002). Hierarchical linear models: Applications and data analysis Methods (2nd ed.). Thousand Oaks: Sage.

Rose, H., \& Betts, J. R. (2001). Math matters: The links between high school curriculum, college graduation, and earnings. San Francisco: Public Policy Institute of California.

Rosenbaum, P. R. (1986). Dropping out of high school in the United States: An observational study. Journal of Educational Statistics, 11(3), 207-224.

Roy, S., \& Casper, B. (2006). Preparing for employment: On the home front. NCSET Parent Brief. Retrieved May 2, 2008, from www. ncset.org/publications/viewdesc . asp . $\mathrm{id}=2844$

Rubin, D. B. (1974). Estimating causal effects of treatments in randomized and non-randomized studies. Journal of Educational Psychology, 66, 688-701.

Schneider, B., Carnoy, M., Kilpatrick, J., Schmidt, W. H., \& Shavelson, R. J. (2007). Estimating causal effects: Using experimental and observational designs. Washington, DC: American Educational Research Association.

Smith, J. B. (1996). Does an extra year make any difference? The impact of early access to Algebra on long term gains in mathematics attainment. Education Evaluation and Policy Analysis, $18(2), 141-153$.

Thompson, B., Diamond, K. E., McWilliam, R., Snyder, P., \& Snyder, S. W. (2005). Evaluating the quality of evidence from correlational research for evidence-based practice. Exceptional Children, 71(2), 181-194.

Wagner, M., Blackorby, J., Cameto, R., \& Newman, L. (1993). What makes a difference? Influences on postschool outcomes of youth with disabilities. The third comprehensive report from the National Longitudinal Study of Special Education Students. Menlo Park, CA: SRI International.

Wagner, M., Marder, C., Levine, P., Cameto, R., Cadwallader, T., \& Blackorby, J. (2003). The individual and household characteristics of youth with disabilities. A report from the National Longitudinal Transition Study-2 (NLTS2). Retrieved September 4, 2009, from http://www.nlts2.org/reports/2003_08/nlts2_report_2003_08_com plete.pdf

Wagner, M., Newman, L., Cameto, R., \& Levine, P. (2005). Changes over time in the early postschool outcomes of youth with disabilities: A report of findings from the National Longitudinal Transition Study (NLTS) and the National Longitudinal Transition Study2 (NLTS2). Menlo Park, CA: SRI International.

Wagner, M., Newman. L., Cameto, R., Levine, P., \& Marder, C. (2003). Going to school: Instructional contexts, programs, and participation of secondary school students with disabilities. A report of findings from the National Longitudinal Transition Study-2 (NLTS-2). Retrieved on October 1, 2009, from http://www.nlts2.org/reports/ 2003_12/nlts2_report_2003_12_complete. pdf 


\section{Strategies for Teaching Students With Special Needs Methods and Techniques for Classroom Instruction}

\section{KATHLEEN M. MCCOY}

The target audience for this book is elementary teachers who teach in inclusive settings with special needs children in their class. The focus is on reading evaluation and reading methods, literacy in the language arts, mathematics evaluation and mathematics instruction, and ideas for the social aspects of inclusion.

The book gives proven methods, practical guidelines, and new innovations for classroom instruction. Vignettes, key terms, the IEP process, and informal assessment are all part of this new text. It also covers low-incidence and high-incidence disabilities and creative ideas for managing and organizing classroom time.

The author and the contributors are highly experienced professionals with classroom teaching backgrounds.

\section{Special Features}

- Provides nuts-and-bolts ideas for teachers to enhance organizational skills.

- Provides numerous suggestions and examples for conducting informal assessment.

Shows classroom activities to facilitate success in both academic and social experiences in the schools and the community.

- Special focus on reading methods showing interventions, strategies, and the perfect literacy model for the needs of the student.

\section{2 pages / paperback / ISBN 978-0-89108-328-3}


Will, M. (1984). OSERS programming for the transition of youth with disabilities: Bridges from school to working life. Washington, DC: Office of Special Education and Rehabilitation Services, U.S. Department of Education.

\section{Professional update}

\section{The Division of International Special Education and Services (DISES) - CEC}

July $11-14,2010$

Riga, Latvia

Contact: www.cec.sped.org

\section{The Division on Autism and \\ Developmental Disabilities - CEC}

January 20-22, 2010

Maui, Hawaii,

Sheraton Maui Resort, Ka'anapali Beach near Lahaina

Contact: Cindy Perras, Conference Coordinator

Cindy.perras@cogeco.ca

www.dddcec.org
Wilson, M. (2008). Math course taking and achievement among secondary students with disabilities: Exploring the gap in achievement between students with and without disabilities. Unpublished doctoral dissertation, University of Maryland, College Park.

\section{Saskatchewan CEC 2009 Fall Conference}

December 3-5, 2009

Radison Hotel Saskatoon, SK, Canada

Contact: www.saskcec.ca

Council of Administrators of Special Education (CASE) Winter Institute

January 27-29, 2010

Sheraton Clearwater Beach, FL

Contact: Luann Purcell

Cindy.perras@cogeco.ca

478-333-6892

1purcell@casecec.org

www.casecec.org

\section{PERMISSIONS AND COPYRIGHT}

All rights are reserved. No part of this publication may be reproduced, photocopied, faxed, stored in a retrieval system, or transmitted in any form or by any means, electronic, mechanical, recording or otherwise, without the prior written permission of the publisher.
Back issues are available for sale. Reproduction requires permission and payment of fees. It is illegal and a violation of federal copyright law to reproduce this publication without permission. Direct all inquiries to the permissions editor. 